\title{
PREPARATION OF PHOTOGRAMMETRIC ARCHIVE DOCUMENTATION FOR SCIENTIFIC AND OTHER RESEARCH
}

\author{
Saša Bakračit, \\ Siniša Drobnjak', \\ Saša Stanković, \\ Ana Vučićević1, \\ Nikola Stamenković2
}

${ }^{1}$ Military Geographical Institute, Belgrade, Serbia

${ }^{2}$ Ministry of Defence,

Belgrade, Serbia

\begin{abstract}
:
Preparation of the archive photodocumentation data is an important step in information processing for numerous scientific and non-scientific research. For scientific research it can be exploration of phenomena such as: soil erosion, landslide, forest changes and vegetation cover, urban changes related to settlements, etc. Further data analysis can provide information about nature and trend of the problem, as well as conclusions for taking preventive and corrective measures. This paper emphasizes presentation of data preparation method from the Military Geographical Institute photodocumentation archive of aerial photogrammetrical images. The paper also contains the part conected with spatial database model of aerial films.
\end{abstract}

Keywords:

Military Geographical Institute, aerial photogrammetric images, archive photodocumentation, digitalization, metadata.

\section{INTRODUCTION}

The main objective of this paper is focused on the presentation of data from the Military Geographical Institute Archive of Photodocumentation (MGI Archive) to the part related to scanning of photogrammetric images. The auxiliary goal is to present to scientific and general public the possibility of using data from the Archive of Photodocumentation for scientific and other researches. In addition to stated goals, the article wishes to emphasize the scientific value of data that are part of Archives. It is considered that the potential of Archives data in the scientific sense is large and can be a good material and a starting point for numerous spatial research. Main and the most important contents of the Archive are aerial photogrammetrical images [5], in addition to other content that consists of: Aerial survey reviews by years, aerial photogrammetry survey registers and supporting map sheets.

The archive dates back to 1950, called the Fototeka, and contains 5,780 inventory units, of which 3,800 are films. 1980 other inventory units are predominantly photograms, which are not subject to processing this article.

It is important to point out that during the preparation of aerial photogrammetric films of the selected area, which is intended to be analyzed or digitized only [3], actions and procedures related to the their preparation are of considerable importance. 
An important role in the preperation for the further use of archival aerial photographs has spatial databale model of aerial photogrammmetric films.

\section{PRESENTATION OF ARCHIVE CONTENT AND DATA PREPARATION}

The Military Geographical Institute photodocumentation archive was formed with the task of preserving the most important results of the aerial photogrammetric survey as well as data and survey records (location, conditions, years, etc.) [1].

Preservation of the photodocumetnation started in 1950. More than $70 \%$ of films were created for the topographic map production at a scale 1:25,000 (TM25) and topographic maps at a scale 1: 50,000 (TM50). In the first cycle of aerial photogrammetric acquisition for these purposes, a total of $86 \%$ of the territory of the SFRY was recorded, up to 1957 at a scale 1: 20,000, 1968 at a scale of 1:22,500 and 1:27,000, 1959 at a scale $1: 30,000$, and since 1960 at a scale of $1: 32,000$ and 1:33,000. The second cycle of aerial photogrammetric acquisition (which as a result gave the second edition of TM25) was realized in the period $1967-1979$. About $80 \%$ of the territory of the SFRY was recorded, mostly at a scale 1: 32,000 . In the period from 1979 to 1984 , an aerial acquisition was undertaken for the purpose of the second edition of the map at a scale $1: 50,000$. On this occasion, $92 \%$ of the territory of the SFRY was recorded, at a scale 1: 45,000 to $1: 50,000$.

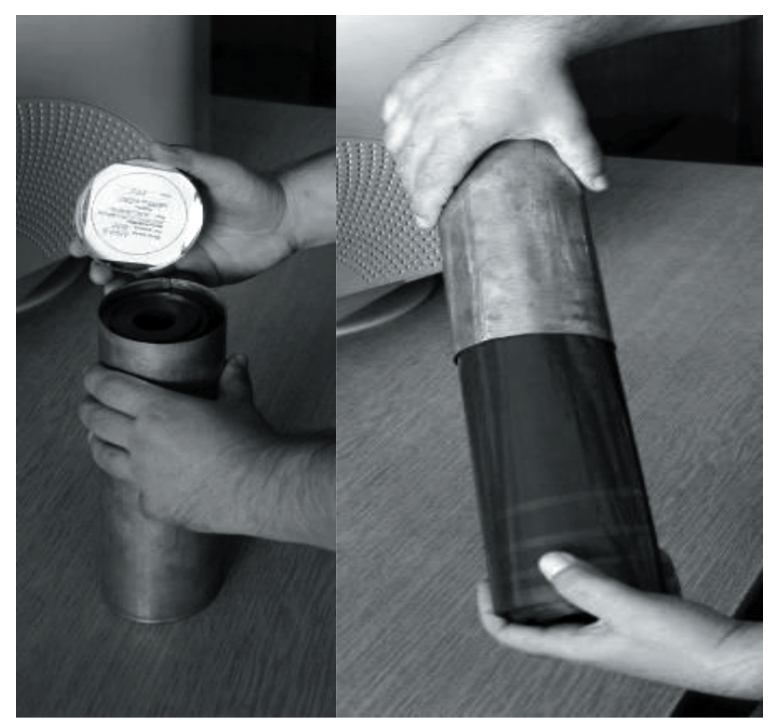

Fig. 1. Film in tube - old type
Other materials were created as a result of the aerial acquisition performed by MGI for the most diverse needs: aerial photogrammetric survey for production of the TM25 third edition and various acquisitions made in large scale, among which are acquisitions for the production of the basic state map at a scale 1: 5.000 and 1: 10,000 (whose design was otherwise under the jurisdiction of the Republic Geodetic Authority, and MGI occasionally assisted in accomplishing this task and retained copies of negatives) and survey of the military complexes [1].

According to existing records, the Archive has a total of 5,780 inventory units: 3,800 films and 1980 other inventory units, mostly photograms. Films are stored in tubes - sheets or plastic cylinders with a base diameter of $6 \mathrm{~cm}$ and height of $20 \mathrm{~cm}$ (old type (Figure 1 - film mark $4886)$ ), or in tube with diameter $8 \mathrm{~cm}$ and height $25 \mathrm{~cm}$ (newer type) made of plastic (Figure 2 -left). Cover of each film is lebeled with unique archive (catalog) number - the number assigned to films by the number one "up" (in the rising row), and on the inside of the cover basic information about the film (picture 2-right) is recorded.

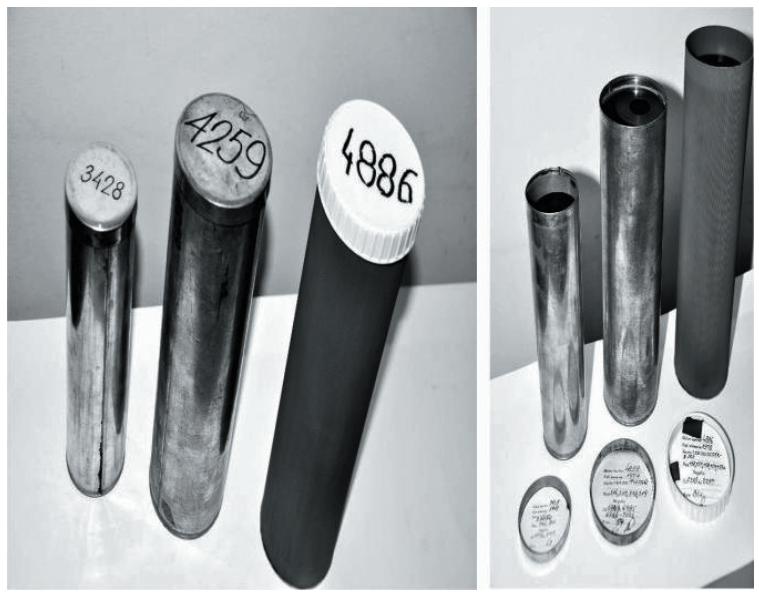

Fig. 2. Types of tubes and labels on lids

The oldest film in the archive is called Split, Omiš, under serial number 1 with 34 images, and the number of the first image is 3844 .

\section{Other materials}

In addition to film negatives and positives, the Archive also contains records of films and images. Those are: 
- Review books of aerial photogrammetric acquisition ordered by years

- Register of aerial photogrammetric acquisition

- accompanying sheets

\section{Review books of aerial photogrammetric acquisition}

These books have been in existence since 1950. There are eight books of A4 format, with a total of 611 pages. Each book covers a period of several years and begins with content that has following elements:

- name of the work area (acquisition area)

- The year of photogrammetric acquisition

- acquisition condition

- page (from - to)

In adittion or next, for each work area (works area are chronologically ordered), following data is given:

- the number of the accompanying sheet

- archival (catalog) film number

- the number of acquisition line

- name of the work area - task (acquisition area)

- the number of the first image in acquisition line

- the number of the last image in acquisition line

- the number of images in acquisition line

- remarks (data about scale and acquisition technique $)^{1}$

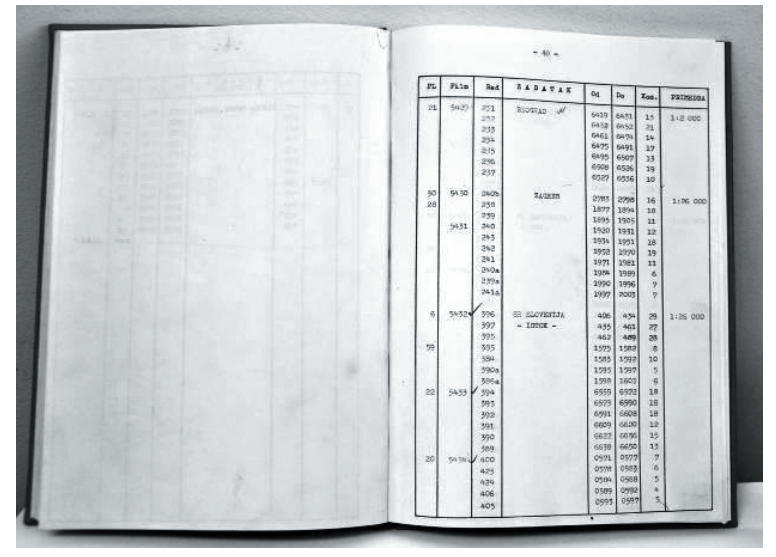

Fig. 3. Review book of aerial photogrammetric acquisition

1 This is how books were kept since 1971; until then they were guided in a way that was slightly different from the one described: they did not contain the number of the accompanying sheet and the number of images in a acquisition line, and the name of the map at a scale 1:300,000 on which the work area is located is entered.

\section{Registers of aerial photogrammetric acquisition}

These are map albums, mostly at a scale of 1:300,000, with lines of aerial photogrammatic acquisition by years. Each line is marked with a line that connects nadir of the first and last image in acquisition line and number (which is unique for that year). Also, numbers of the first and last image are printed. Due to the fact that data for the 10 years of aerial photogrammatic acquisition are entered on the map sheet, lines related to the same year are presented with lines of the same color and type, and in a special legend, a review of color and line types is given acording to year of aerial photogrammatic acquisition.

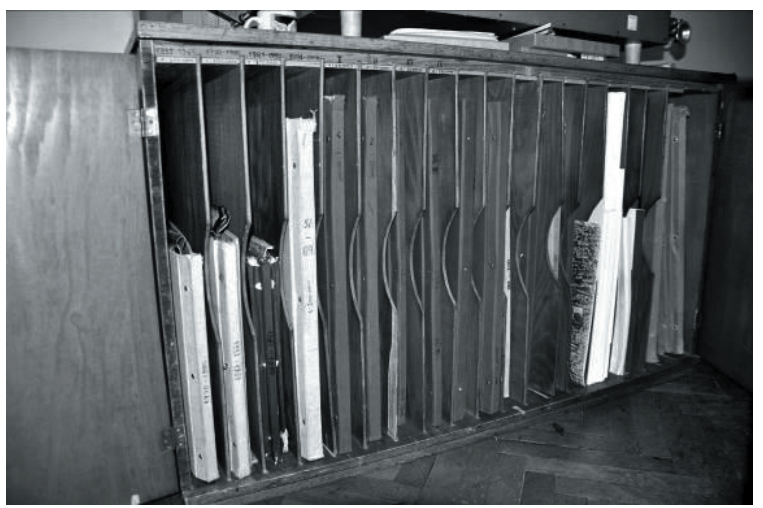

Fig. 4. Storage of aerial photogremmetric acquisition registry

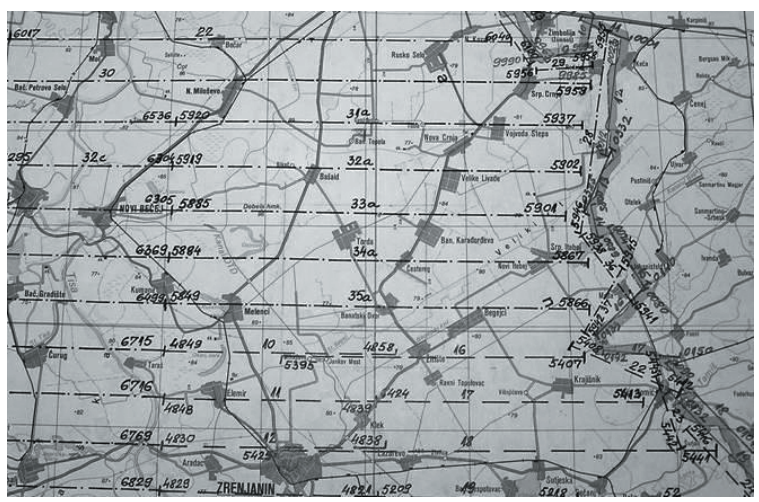

Fig. 5. Part of map sheet with aerial photogremmetric acquisition lines 


\section{Accompanying sheets}

Accompanying sheets are formed for each recorded aerial photogrammetric survey. They represent specific metadata for each aerial image, and are numbered one upward, within one year. Sheets are A4 format, there are 3,048 of them with a total of 6,097 pages. Until 1957, they were done on a single paper, and then on the second, modified form named ("accompanying sheet").

The first form accompanying sheet header contains the following information:

- the number of the accompanying sheet

- acquisition area (according to map at scale 1: 100,000)

- Photogrammetric camera and its number

- The number of cassette

- film number

- longitudinal switching

- flight height in meters

- film (panel) and sensitivity

- Exposure, aperture and filter

- Meteorological conditions in acquisition period

- date and time of acquisition (alternatively: year and type of aircraft)

Other data is entered in a table that contains the following columns:

- the number of line

- flight direction (in relation to the compass direction)

- number of images (from - to)

- Remarks (acquisition scale, microlocation, revisit period, etc.)

The second form, which was conducted since 1957, has two sides. In the first, the following information is entered in the header:

- the number of the accompanying sheet

- year of acquisition

- a plane

- longitudinal switching

- The number of the film box

- film type (panels) and sensitivity

- photogrammetric camera and its number

- the number of cassette

- cartridge

- focal length

Then follows the table with following columns:

- the film number

- date of acquisition
- flight direction (in relation to the compass direction)

- the number of acquisition line

- start and end number of the image (so-called negatives registration numbers)

- start and end number of the image retained for further processing (so-called definitive negative numbers )

- Name of the map sheet at a scale 1: 100,000 on which the workarea is located

- Exposure data (exposures, blend, screen)

Before filling the table, work area code was entered. The first page ends with date and signature of the person who "draw the line and entered final negative numbers". On the other side of the accompanying form, recorder's pilot's and scouts data are entered camera's remarks and signature the, as well as relating to development of the film: who developed, descriptive estimate after chemical processing, length of the film in meters, where and when film was developed and signed by a photolaborant.

- flight height in meters

- film (panel) and sensitivity

- Exposure, aperture and filter

- Meteorological conditions in survey period

- date and time of acquisition (alternatively: year and type of aircraft)

Such prescribed accompanying sheet was marked "AS Form No. 16". In 1985, it was modified to a lesser degree (Figure 6), since on the first page instead of the work area code, name of the task (ie location of the recording) was entered, and length of the film in meters was added; on the other side was added a section on meteorological conditions during the acquisition, some more detailed data on photolaboratory processing of the film (developer used and its concentration, temperature and development time) were requested.

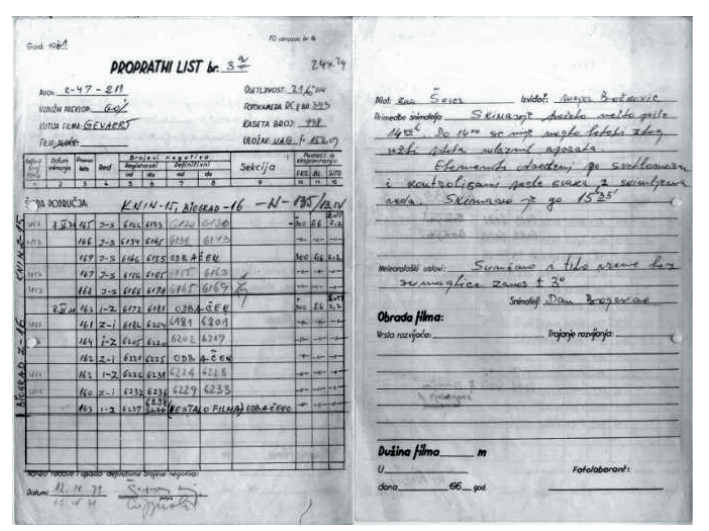

Fig. 6. Example of the accompanying sheet 
Preparing aerial images for data collection

In concrete case, the preparation or the extraction of photogrammetric images involves following steps:

- Insights into acquisition albums include those albums that contain selected area and epoch - year of acquisition

- From the selected album, we download number and order of the image from subject area

- From the review book of aerial photogrammetric acquisition, according to scale and year of recording, we found the number of acquisition line, and based on that, desired film is found in the requested acquisition scale.

After selecting film by epochs-years of acquisition, a scanning process is performed, i.e. translation into digital form.

\section{MODELING OF THE SPATIAL DATABASE FOR AERIAL FILMS}

The spatal database would be relational and within the database management system. This approach is the most widespread in moder Geographical Informatom System, it is reliable and satisfies most user needs. Modeling the database will be directed using logical and physical database models. A logical database model consists of entities and attributes, as well as the relationship between entities. A physical database model is a query-optimized model and model optimized for certain database implementations and application thet need to comunicate with the database. In figure 7 , the database management system and attribute table (tbl Row) are displayed.

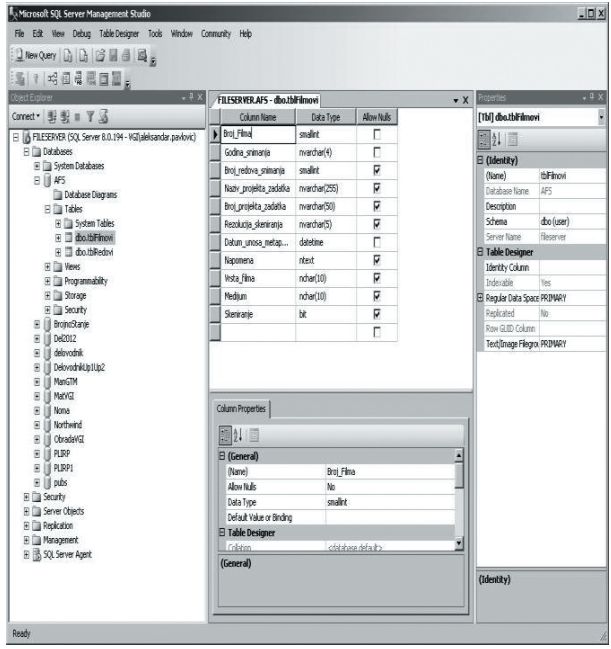

Fig. 7. Database management system and attribute table (tbl - Row)
This database model consists of three entities (tables): tbl - films, tbl - row, and tbl - users. The system is designed so that it can easily be supplemented and expanded, depending on future requirements.

For the modeling of a database, it is necessary to use a dedicated tool, for example, $\mathrm{CASE}^{2}$ tool ERwin Data Modeler r7.3.

For the development of a database a Microsoft SQL Server database management system can be used. For the better specification of the user's requirements and the production of better documentation, a modeling in a language is necessary, for example, $\mathrm{UML}^{3}$.

Creating a logical application model should be donewith object-oriented modeling in UML language. Application part can be done in Microsoft Visual Studio.

\section{CONCLUSION}

The use of aerial photogrammetric images in field analysis provides a good basis for a variety of spatial research [2]. These refinements give a brighter picture of past events with the possibility of comparing periods of time and the possibility of predicting future events [4]. To this end, this paper is important because it provides an overview of preparatory activities up to the phase of aerial photogrammetric scanning, i.e. until their digitization. The main part of the paper emphasizes the significance of the MGI's Photodocumentation Archives, through the consideration of possible use for scientific and other purposes. Considering content of the Archive and manner of data preparation, the answer to main goal of the research is given. Demonstration of the preparation of aerial photogrammetric images, up to the scanning phase, requires good data preparation and information, and in particular, the use of auxiliary means such as: Review books of aerial photogrammetric acquisition ordered by years, Register of aerial photogrammetric acquisition and accompanying sheets. An important part of the paper is about modeling spatial database of aerial films, as one of the important step in further application of aerial film and for they easily display and use. It can be concluded that the MGI's Photodocumentation Archive with its main content - aerial photographs, i.e. aerial images have great potential for scientific and other research.

2 engl. Computer Aided Software Engineering

3 engl. Unified Modeling Language 


\section{REFERENCES}

[1] S. Bakrač, Z. Milonjić, D. Đorđević, Z. Srdić, and S. Tatomirović, "Using the Military Geographical Institute photogrammetric documentation archive data for scientific and other research - the necessity and importance of digitization," vol.1, pp. 4043, April 2017 [International Scientific Conference, Belgrade, Serbia: Singidum University]

[2] R.J Fensham and R.J Fairfax, "Aerialphotography for assessing vegetation change: A review of applications and the relevance of findings for Australian vegetation history," Australian Journal of Botany, vol. 50(4), pp. 415-429, 2002.
[3] S. Jauhiainen, M. Holopainen, and A. Rasinmaki, "Monitoring peatland vegetation by means of digitized aerial photographs," Scandanavian Journal of Forest Research,. vol. 22(2), pp. 168-177, 2007.

[4] A.S. Laliberte, A. Rango, K.M. Havstad, J.F. Paris, R.F. Beck, R. McNeely, and A.L. Gonzalez, "Object-oriented image analysis for mapping shrub encroachment from 1937 to 2003 in southern New Mexico," Remote Sensing of Environment, vol. 93, pp. 198-210, 2004.

[5] S. Tomić, Standardization of geoinformations obtained by photogrammetry and remote sensing. Faculty of Civil Engineering, Department of Geodesy and Geoinformatics, Belgrade: University of Belgrade,.2010. 